\title{
ЦЕЛИ И ЗАДАЧИ СУДЕБНО-ЭКСПЕРТНОЙ ДЕЯТЕЛЬНОСТИ В РЕАЛИЯХ СОВРЕМЕННОСТИ
}

\author{
Овсянникова И.М. \\ Национальный научный чентр «Институт судебных экспертиз \\ им. Засл. профр. Н.С. Бокариуса» Министерства юстиции Украины, \\ Харьков, Украина
}

Предварительный анализ проблем судебно-экспертной деятельности показывает существование необходимости в согласованном и целостном понимании ее сущности, значении и перспективах развития в современных условиях. Статья посвящена проблемным вопросам теоретического и административно-правового характера, которые имеют место быть при рассмотрении судебно-экспертной деятельности как объекта исследования, и которые требуют своего эфрфективного разрешения в условиях современности. Значительное внимание в статье уделяется анализу публикаций ученых, наработок исследователей и законодателей в данной сфрере, который, в первую очередь, свидетельствует о различие во взглядах на содержание одного из таких базовых понятий как «судебно-экспертная деятельность». $B$ исследовании подчеркивается, что основополагающим при рассмотрении судебно-экспертной деятельности является определение ее субъектов, а также эффрективность достижения ими поставленных челей и задач. Отмечается важность международного сотрудничества субъектов судебно-экспертной деятельности.

Ключевые слова: деятельность, судебно-экспертная деятельность, чели, задачи, эфрфективность.

В современных условиях судебная экспертиза играет все более существенную роль в общественной жизни каждого государства. Однако, перед тем как начать дискуссию о задачах судебно-экспертной деятельности, необходимо сосредоточить внимание на том, что на данном этапе развития, нормами законодательства Украины не урегулирован вопрос терминологического определения самого понятия «судебно-экспертная деятельность». Несмотря на неоднократные обращения внимания к данной проблеме со стороны законодателей, экспертов-практиков и ученых, данный вопрос остается все также актуален и на сегодняшний день. Анализ научных трудов и законодательной базы дают основание говорить о неоднозначности подходов к определению данного понятия.

Так, в действующем Законе Украины «О судебной экспертизе», хотя и отмечено, что им определяются правовые, организационные и финансовые основы судебно-экспертной деятельности в целях обеспечения правосудия Украины независимой, квалифицированной и объективной экспертизой, ориентированной на максимальное использование достижений науки и техники, однако само определение судебно-экспертной деятельности в законе отсутствует [1]. В литературе используются такие определения как: «экспертная деятельность», «судебноэкспертная деятельность», «экспертно-криминалистическая деятельность», «деятельность

\footnotetext{
Адрес для корреспонденции: Овсянникова Инесса Михайловна, старший научный сотрудник, Национального научного центра «Институт судебных экспертиз им. Засл. проф. Н.С. Бокариуса» Министерства юстиции Украины, 61177, Украина, г. Харьков, ул. Золочевская, 8а, ННЦ «Институт судебных экспертиз им. Засл. проф. Н.С. Бокариуса», тел:+380 97971971 3; +380 (57) 372-17-86, e-mail: inessa_ovs@ukr.net
} 
экспертно-криминалистических подразделений», содержание которых учеными трактуются поразному. Таким образом, на сегодняшний день понятие экспертной деятельности и ее содержание ни учёными, ни законодателями четко не сформулированы.

Справочная литература определяет судебную экспертизу как регламентированное процессуальным законом исследование экспертом на основе специальных знаний конкретных обстоятельств дела с целью установления фактов, имеющих существенное значение для установления объективной истины по делу [2, 3]. Проводя сравнительный анализ понятий «экспертная деятельность» и «судебно-экспертная деятельность», следует подчеркнуть, что понятие «экспертная деятельность» по своему содержанию значительно шире понятия «судебно-экспертная деятельность», ведь в судебно-экспертной деятельности, так же как и в любой другой экспертной деятельности, исследование основано на использовании знаний специалистов в определенной сфрере знаний, однако, оно осуществляется в сфрере судопроизводства, где его объектами являются вещественные доказательства по соответствующему уголовному делу, гражданскому делу или делу об административных правонарушениях [4, 5].

В общем, под экспертной деятельностью, которая может проявляться в различных сферах (научной, экономической, медицинской и т.д.), понимается компетентное исследование вопроса, требующее наличия специальных знаний и представления мотивированного заключения [6]. Рассматривая различия между понятиями «экспертной» и «судебно-экспертной» деятельностью, И.В. Пирог определяет последнюю как регламентированную законодательством деятельность лиц, владеющих специальными знаниями и уполномоченных сторонами судебного процесса на проведение действий, содержанием которых является исследования определенных объектов, процессов или явлений с целью получения научно-обоснованных заключений для их использования при расследовании и судебном рассмотрении дел [7].

М.Я. Сегай рассматривает «судебно-экспертную деятельностью» в качестве объекта познания судебной экспертологии и определяет ее как деятельность государства, юридических и фризических лиц по обеспечению правосудия независимой, объективной и квалифицированной экспертизой, осуществляемой профессиональными (аттестованными) судебными экспертами [8].

Э.Б. Симакова-Ефрремян предлагает определять судебно-экспертную деятельность как вид деятельности, связанный с организацией и проведением судебных экспертиз и других экспертных исследований с целью обеспечения правосудия независимой, квалифицированной и объективной экспертизой, ориентированной на максимальное использование достижений науки и техники [9 с.122].

И.В. Сташевская дает определение судебно-экспертной деятельности исключительно как особому виду человеческого труда, результат котрого может стать решающим инструментом при определении истины и защите прав человека [10]. Похожего мнения придерживается и А. В. Дудич, который отмечает, что судебно-экспертная деятельность должна выступать профессиональной деятельностью судебно-экспертных учреждений в целом и эксперта в частности [11].

Некоторые ученые определяют судебно-экспертную деятельность как особый вид деятельности, связанный с:

- организацией и проведением судебных экспертиз, экспертных исследований, направленных на обеспечение уполномоченных лиц (органов), юридических и физических лиц независимыми, квалифицированными и объективными выводами, ориентированными 
на максимальное использование достижений науки и техники;

- созданием и усовершенствованием научно-методической базы в области криминалистики и судебной экспертизы;

- государственным управлением в судебно-экспертной деятельности [12].

Проведенный анализ научных подходов дает основание заявить, что среди учених до сих пор ведуться споры о том, что же такое «судебно-экспертная деятельность». Несмотря на разность существующих мнений, в целом их можно разделить на две основные группы:

- группа ученых, которые считают, что судебно-экспертную деятельность нужно ограничивать только деятельностью, которая происходит в пределах судебно-экспертных учреждений, ведь большинство экспертиз проводится именно в них;

- группа ученых, которые отмечают сложности внутреннего содержания и структуры судебно-экспертной деятельности, и потому, дополнительно относят к ее содержанию общие аспекты деятельности по экспертному обеспечению правосудия [13].

В наиболее общем плане, понятие «деятельность» фрормулируется фрилософией как деятельность человека. Еще Аристотель в «Метафизике» писал: “Дело - цель, а деятельность - дело, почему и «деятельность» (energeia) производна от «дела» (ergon) и нацелена на «осуществленность» (entelecheia)» [14]. Уже на этой стадии развития науки деятельность увязывается с двумя другими категориями: цель (целенаправленность) и результат (результативность). Любая деятельность предопределяется определенным набором ценностей и целей. Если ценность отвечает на вопрос: для чего нужна та или иная деятельность, то цель - что должно стать результатом такой деятельности. Иными словами, цель представляет собой идеальный образ ожидаемого результата [15]. Следует отметить, что судебно-экспертная деятельность сочетает в себе черты, присущие любой экспертной деятельности, в частности ее общественный характер, целеустремленность, плановость, систематичность [16].

Наряду с термином «цель» выступает такое понятие как «задача». Поскольку данный термин не является фрилософской категорией, его определение с философрской точки зрения в профрильных словарях отсутствует. Вместе с тем, именно термин «задача» наиболее часто используется в законодательстве для определения конкретных результатов на достижение которых нацелена деятельность субъектов. Наличие предусмотренных законом специальных субъектов судебно-экспертной деятельности является фрундаментальным принципом в ее осуществлении. В соответствии со статьей 7 Закона Украины «О судебной экспертизе», к субъектам, осуществляющим судебно-экспертную деятельность относятся государственные специализированные учреждения, их территориальные фрилиалы, экспертные учреждения коммунальной формы собственности, а также судебные эксперты, которые не являются работниками указанных учреждений и другие специалисты (эксперты) из соответствующих областей знаний в порядке и на условиях, определенных упомянутым Законом [1]. При этом, прерогатива и монополия на проведение судебно-экспертной деятельности связанной с проведением криминалистических, судебно-медицинских и судебно-психиатрических экспертиз отдана исключительно государственным специализированным учреждениям, к которым в Украине отнесены:

- научно-исследовательские учреждения судебных экспертиз Министерства юстиции Украины;

- научно-исследовательские учреждения судебных экспертиз, судебно-медицинские и 
судебно-психиатрические учреждения Министерства здравоохранения Украины;

- экспертные службы Министерства внутренних дел Украины, Министерства обороны Украины, Службы безопасности Украины и Государственной пограничной службы Украины.

Следует отметить, что цели и задачи деятельности обозначенных выше государственных специализированных учреждений определяются в первую очередь их уставами или же положениями о них. Вместе с тем, последние должны коррелироваться с основными конституционными ценностями государства, которыми в первую очередь руководствуется в своей работе Министерство юстиции Украины - центральный органом исполнительной власти, реализующий государственную правовую политику по вопросам экспертного обеспечения правосудия в Украине. К первоочередным конституционным ценностям следует отнести верховенство права, обеспечение соблюдения прав и свобод человека и гражданина, законность, открытость и прозрачность; ответственность и подотчетность; профессионализмом и т.д. [17].

Анализ уставной и другой специализированной докуменации, а также положений, нормами которых регулируется деятельность научно-исследовательских учреждений судебных экспертиз, в целом показывает, что, безусловно, главной их целью является обеспечение правосудия независимой, квалифицированной и объективной экспертизой, ориентированной на максимальное использование достижений науки и техники.

В реалиях современности, на наш взгляд, одной из актуальных задач стоящих перед субъектами судебно-экспертной деятельности и государством в целом, является активизация международного сотрудничества в сорере судебной экспертизы и криминалистики. Нормами базового закона, регулирующего судебно-экспертную деятельность в Украине и инициирующих международное сотрудничество государственных судебно-экспертных учреждений предусмотрены следующие права:

- возможность включения в состав экспертных комиссий ведущих специалистов других государств (по согласию органа или лица, назначивших судебную экспертизу);

- возможность по установлению международных научных связей (в том числе с учреждениями судебных экспертиз, криминалистики других государств);

- возможность проведения совместных международных научных конференций, симпозиумов, семинаров;

- возможность обмена стажерами, научной информацией и печатными изданиями, а также возможность осуществления совместных изданий в области судебной экспертизы и криминалистики [1].

По мнению А.Н. Клюева, международное научное сотрудничество является как одним из самых действенных средств повышения эффрективности судебно-экспертной деятельности, так и средством вхождения на новые рынки и технологические пространства, где довольно весомую роль должно играть государство [18].

Одним из способов повышения эффективности международного сотрудничества, на наш взгляд, является членство в Европейской сети судебно-экспертных учреждений, которое позволяет открывать новые перспективы коммуникации и сотрудничества для субъектов судебноэкспертной деятельности. Обмен опытом между экспертными учреждениями в первую очередь европейских государств и государств постсоветского пространства - это тот механизм, который обеспечивает развитие собственной эффективной системы судебно-экспертной деятельности в соответствии с современными тенденциями. 


\section{Список литературы}

1. Про судову експертизу: закон України від 25.02.1994 р. № 4038—XII (зі змінами та доповненнями). URL: https://zakon.rada.gov.ua/laws/show/4038-12\#Text (дата звернення 26.04.2021).

2. Аванесян В. В., Андреева С.В. Большая юридическая энциклопедия. Москва: Эксмо, 2007. 687 C.

3. Большой юридический словарь /под ред. А. Я. Сухарева, В. Е. Крутских. 2-е изд., перераб. и доп. Москва: ИНФРА-М, 2003. 704 с.

4. Олійник О. О., Галунько В. В., Єщук О.М. Адміністративно-правове регулювання судово-експертної діяльності: монографрія. Херсон: Грінь Д. С., 2015. 224 с.

5. Пиріг І.В. Поняття та зміст експертної діяльності органів внутрішніх справ. Право України. 2011. № 1. C. 255-261.

6. Головатий М. Ф., Панасюк М. Б. Соціальна політика і соціальна робота: термінологічно-понятійний словник. Київ: МАУП, 2005. 560 с.

7. Пирог И. В. О понятии судебно-экспертной деятельности. Журнал научных публикаций аспирантов и докторантов. URL: http://jurnal.org/articles/2014/uri85.html (дата обращения 26.04.2021).

8. Сегай М. Я. Судебная экспертология: объект, предмет, природа и система науки. Теорія та практика судової експертизи і криміналістики: зб. наук.-практ. матеріалів (до 80-річчя заснування Харківського НДІ судових експертиз). Харків : Право, 2003. Вип. 3. С. 25-32.

9. Сімакова-Єфрремян Е. Б. Про необхідність удосконалення законодавства щодо здійснення судово-експертної діяльності в Україні. Теорія та практика судової експертизи і криміналістики. Харків : Право, 2019. Вип. 19. С. 118- 129. DOI: https: //doi.org/10.32353/khrife.1.2019.09.

10. Сташевська І. В. Негативні наслідки відсутності гарантій незалежності судового експерта в контексті його матеріального та соціального забезпечення. Актуальні питання судової експертизи $i$ криміналістики : зб. матеріалів міжнар. наук.-практ. конфр.-полілогу (м. Харків, 15-16 квіт. 2021 р.). Харків : Право, 2021. С. 80-82

11. Дудич А. В. Експерт як учасник кримінального провадження: дисс. ... канд. юрид. наук: 12.00.09. Одеса, 2016. 253 с.

12. Судові експертизи у процесуальному праві України : навч. посіб. за заг. ред. О. Г. Рувіна. Київ : Видво Ліра-К, 2019. 424 c.

13. Овсянникова І.М. Деякі теоретичні підходи до визначення поняття «судово-експертна діяльність». Актуальні дослідження правової та історичної науки: матер. міжнар. наук.-практ. інтернет-конф. Вип. 30 (м. Тернопіль, 11 березня 2021 р.). Тернопіль: ФО-П Шпак В.Б., 2021. С.22-23. URL: http:// www.lex-line.com.ua/?go=full article\&id=3179 (дата обращения 26.04.2021).

14. Аристотель Сочинения. В 4-х т.: под общ. ред. В.Ф. Асмуса. Москва: Мысль. 1976. Т. 1. С. 246.

15. Кузьмин С. А. Организационно-правовое обеспечение менеджмента качества судебно-экспертной деятельности: дис. ... канд. юрид. наук: 12.00.12. Москва, 2016. 240 с.

16. Кузьмічов В. С., Чорноус Ю. М. Слідча діяльність: характеристика та напрями удосконалення: монографрія. Київ: Нічлава, 2005. 446 с.

17. Бачення, місія, цінності (по данным Министерства юстиции Украины). URL: https://minjust.gov. ua/pages/mission. (дата звернення 12.03.2021).

18. Клюєв О. М. Міжнародне наукове співробітництво - ефективний механізм удосконалення судово-експертної діяльності. Актуальні питання судової експертизи і криміналістики : зб. матеріалів міжнар. наук.-практ. конф.-полілогу (м. Харків, 15-16 квіт. 2021 р.). Харків : Право, 2021. C. $37-39$. 


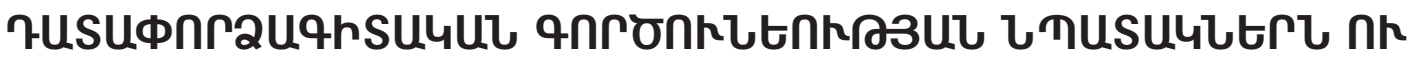

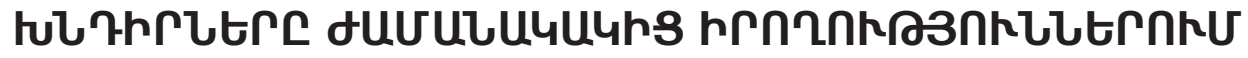

\author{
Oцијшu\&hlnцш h.U.
}

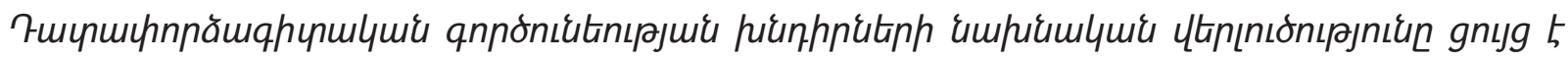

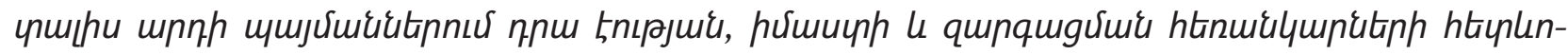

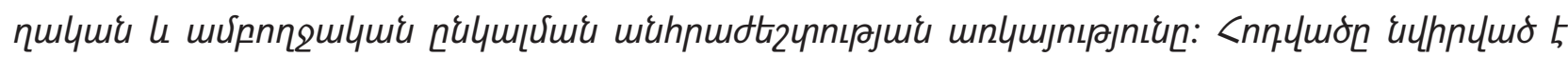

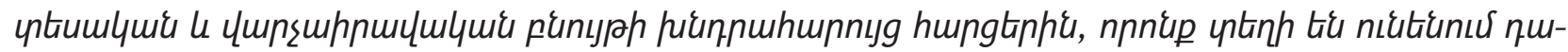

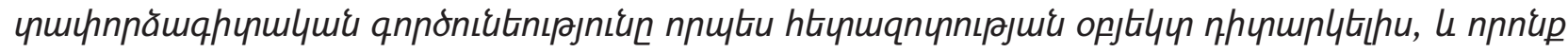

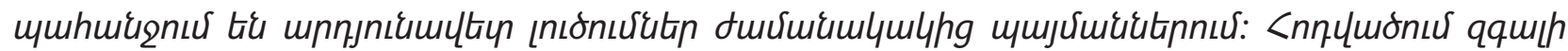

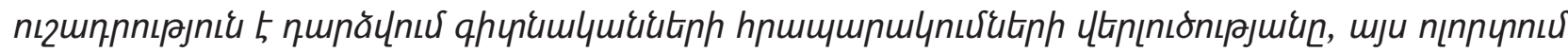

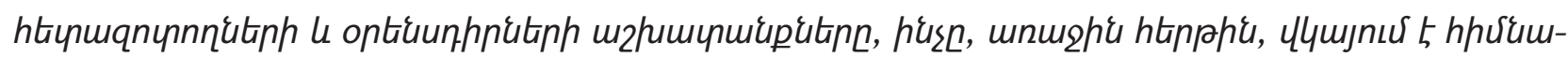

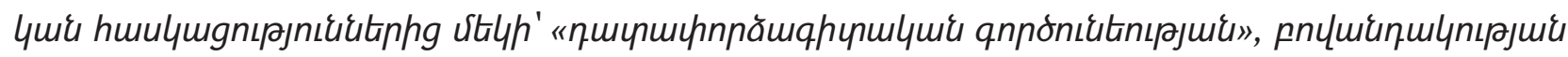

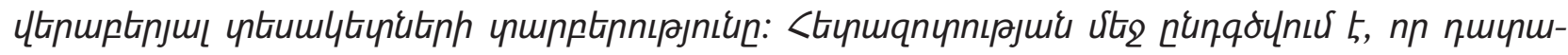

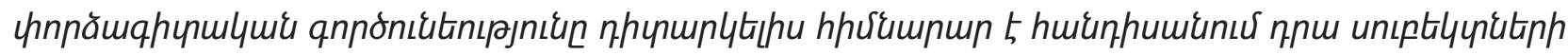

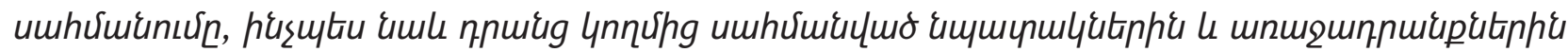

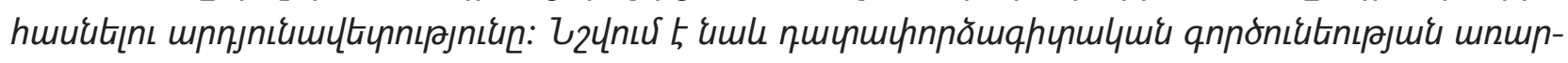

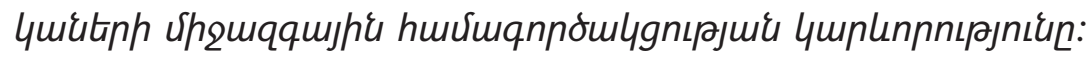

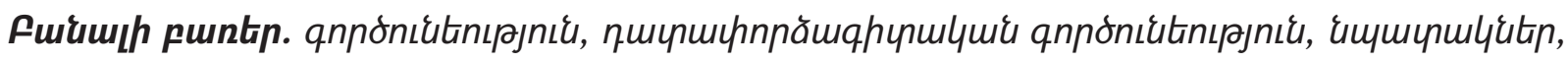

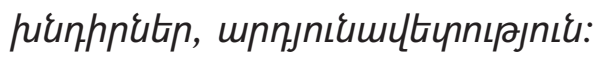

\section{AIMS AND TASKS OF FORENSIC EXPERT ACTIVITY IN THE REALITIES OF MODERN TIME}

\section{Ovsiannykova I.}

Forensic activity problems analysis shows a need of consistent and holistic understanding of its essence, meaning and development prospects in modern conditions. The article is devoted to theoretical and administrative-legal nature problematic issues that take place considering a forensic activity as an object of research, and which require their effective resolution in modern conditions. Considerable attention in the article is paid to the scientific research papers, developments of researchers and legislators in this area, the analysis of which, first of all, testifies to the difference in views on the content of one of such basic concepts as "forensic expert activity".

The study demarks that the definition of forensic expert activity subjects is fundamental when you considering it as well as the importance of the effectiveness of the achievement of their aims and tasks. The article is also demarked the importance of international cooperation of subjects of forensic expert activity as one of the fundamental tasks of the state.

Key words: activity, forensic expert activity, aims, tasks, effectiveness.

Статья поступила: 26.04.2021

Принята к печати: 08.05.2021 